\title{
An innovative practical teaching model based on information technology
}

Jianhua Shi, Hairong Zhong, Bing Lei, Wei Liu, Chengfang Duan, et al.

Jianhua Shi, Hairong Zhong, Bing Lei, Wei Liu, Chengfang Duan, Wei Wang, "An innovative practical teaching model based on information technology," Proc. SPIE 11143, Fifteenth Conference on Education and Training in Optics and Photonics: ETOP 2019, 1114330 (2 July 2019); doi: 10.1117/12.2523269 Photonics: ETOP 2019, 2019, Quebec City, Quebec, Canada 


\title{
An innovative practical teaching model based on information technology
}

\author{
Jianhua Shi*, Hairong Zhong, Bing Lei, Wei Liu, Chengfang Duan and Wei Wang \\ College of Advanced Interdisciplinary Studies, National University of Defense Technology, Changsha 410073, China
}

\begin{abstract}
In traditional teaching model of experimental lesson, the teacher introduces the principles, the devices and the matters needing attention of the experiment to the students before the students begin to do the experiment, the students analyze the result and finish the report after school. If the students have some questions about the result, it's very hard for them to solve the questions through experimental method.

In order to free up class time for students to do experiments, improve the efficiency and effect of experimental teaching, a mini-experiment-teaching APP was developed. It can be used by mobile phones with android or OS system. Through it, the students can watch the teaching videos, finish the fundamental questions(just about the background, the principles, the devices, the matters needing attention of the experiments. ) and discussed with teachers and classmates.

The APP was practiced in experimental lesson of opto-electronic technology, the students must watch the whole teaching video, finish the fundamental questions and get 60 scores before they begin to do the experiment, and must finish analyzing the results of the experiment before they leave the laboratory. The results of practice and survey show that most students prefer the novel teaching model to the traditional teaching model, only one student didn't finish watching teaching video before class. The result of examination shows that the effect of the novel teaching model is better than that of the traditional teaching model, the novel teaching model can also save the teacher's time.
\end{abstract}

Keywords: teaching model, experimental lesson, opto-electronic technology, teaching video

\section{INTRODUCTION}

In recent years, the technologies of computer and internet are developing very fast, and they are promoting the innovation of teaching model. Some new teaching models, such as MOOCs, SPOC, are growing up. They make more people learn specialized knowledge more easily. Now there are so many MOOCs ${ }^{[1]-[5]}$. Our group have studied on MOOCs for a long time and got some results ${ }^{[6]-[7]}$. But our previous study focused on the theory courses.

Practical teaching is very important and our group also pays much attention on $\mathrm{it}^{[8]-[9]}$. In our university, the teaching process of practical lesson is the teacher introduces the principles, devices and the matters needing attention of the experiment (in class)->students do experiment(in class)->students write report(after class). If the students find something uncertain when he is writing the report, it is difficult for him to prove his opinion. For the teacher, introducing the experiment is a repetitive process. In order to improve the efficiency and effect of the practical lesson, our group began to innovate the teaching model of the practical lesson from 2017. A mini-experiment-teaching APP was developed and the students must finish watching the teaching video and answering certain questions and get a good score by the APP before they come to the laboratory and begin the experiment.

The experimental lesson of opto-electronic technology is a very important lesson for the student whose major is optical engineering. It is made of 18 experiments. Each year, more than 100 students have this lesson, about 10 teachers and 2 experimental instructors are needed. Our group decided to practice the new teaching model on this lesson.

\section{INTRODUCTION OF THE TEACHING-ASSISTANT APP}

Nowadays almost every student has a smartphone and uses it frequently, in order to make it convenient for the student to use, a teaching-assistant APP that can be used by smartphone was developed by our group.

*gexin7651@sina.com; phone 086-731-87004142 


\subsection{Installment of the APP}

The APP can be used in the android or OS system. It can be installed very easily. Fig. 1 gives the two-dimensional code of this APP. The student just need to scan the two-dimensional code and the software will set up automatically. Of course, the student also can use it by a computer.

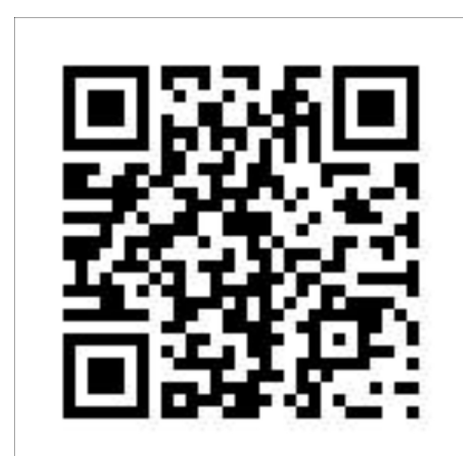

Figure 1. The two-dimensional code of the APP

\subsection{Functions of the APP}

The APP is made of two main parts, the administrator module and the student module, as showed in Fig.2 (a). In the administrator module, the teacher can manage the students, upload the teaching video, lecture notes, teaching material, and the exercises, etc., know whether the students have finished watching the teaching video and preview questions before class, and check the students' answers. In the student module, the student can watch the teaching video, read the lecture notes and teaching material, finish the exercise. Before the experiment, the student know his score, the right answer of each question, and whether he gets the qualification to begin the experiment.

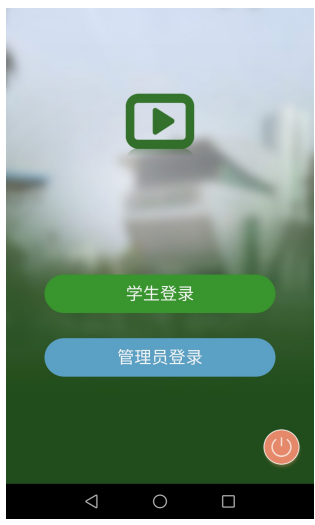

(a)

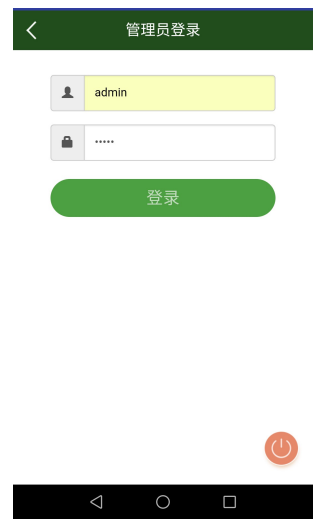

(b)

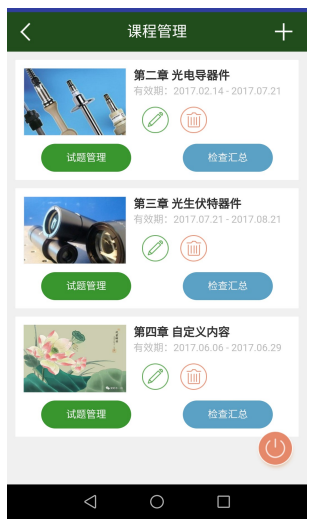

(c)

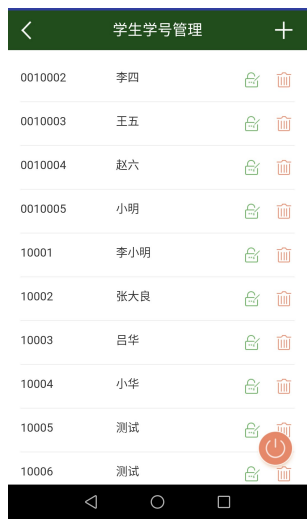

(d)

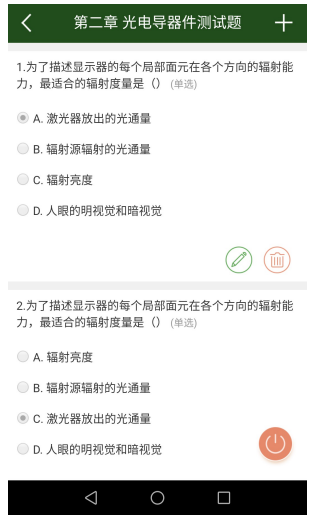

(e)

Figure 2. The components of the APP

(a.) the two main parts of the APP (b) the module for administrator (c) the module for the management of the course (d) he module for the management of the students (e) the test question

\subsection{Teaching video}

Teaching video is the main component of the internet teaching. In order to make the student understand the experiment deeply, the principle, devices, process, control software and the matters needing attention of the experiment are introduced in the teaching video. The students can watch the video repeatedly. In order to improve the sense of the presence, the teaching video is recorded in the laboratory with students. Fig. 3 gives the snapshot of the teaching video. There are some interactions between the teacher and students. If the students have any questions, they can put the questions to the teacher. 


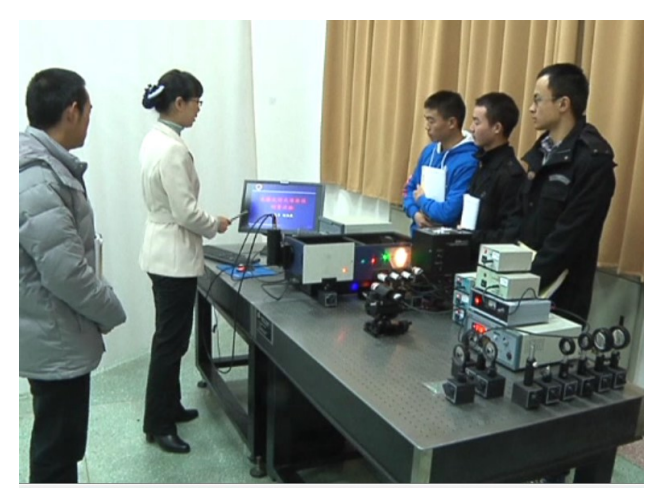

Figure 3. The snapshot of the teaching video

\subsection{Preview questions}

Preview questions are used to make the students to know whether they have mast the knowledge well enough to do the experiment. They are not too difficult, but very important. The students must finish them and get a good score before they begin the experiment. Table 1 gives the choice questions and table 2 gives the judgment questions of the experiment on the measurement of the light sources' characters(It's a basic experiment that every students must do it). They come from the most important contents of the experiment.

Table 1. Choice questions of experiment on the measurement of the light sources' characters.

\begin{tabular}{|c|c|c|}
\hline Number & Questions & Choices \\
\hline 1 & $\begin{array}{l}\text { Which characters can be got through analyzing } \\
\text { the spectral line of the light source? }\end{array}$ & $\begin{array}{l}\text { A. peak wavelength } \text { B. distribution of light intensity } \\
\text { C. beam divergence angle } \quad \text { D. width of spectral line }\end{array}$ \\
\hline 2 & $\begin{array}{l}\text { Which type does the spectral line of the } \\
\text { fluorescent lamp belong to? }\end{array}$ & $\begin{array}{ll}\text { A. line spectrum } & \text { B. continuous spectrum } \\
\text { C. hybrid spectrum } & \text { D. banding spectrum }\end{array}$ \\
\hline 3 & $\begin{array}{l}\text { Which light sources will be tested in the } \\
\text { experiment? }\end{array}$ & $\begin{array}{l}\text { A. bromine-tungsten } \quad \text { B. LED } \\
\begin{array}{ll}\text { C. LD } & \text { D. He-Ne laser }\end{array}\end{array}$ \\
\hline 4 & $\begin{array}{l}\text { Where is the focal point of the first cylindrical } \\
\text { mirror in the spectrometer? }\end{array}$ & 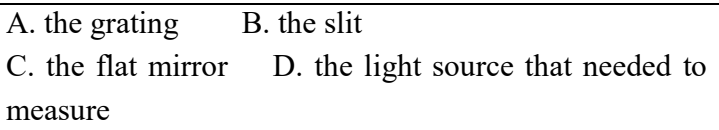 \\
\hline 5 & $\begin{array}{l}\text { How does the spectrometer scan the different } \\
\text { wavelength light? }\end{array}$ & $\begin{array}{l}\text { A. rotate the grating } \quad \text { B. move the detector } \\
\begin{array}{ll}\text { C. use linear array detector } & \text { D. move the grating }\end{array}\end{array}$ \\
\hline 6 & Which kind detector is used in this experiment? & $\begin{array}{lll}\text { A. PMT } & \text { B. PD } & \text { C. PC D. pyroelectric detectors }\end{array}$ \\
\hline 7 & $\begin{array}{l}\text { Which light source can be used to calibrate the } \\
\text { spectrometer? }\end{array}$ & $\begin{array}{ll}\text { A. bromine-tungsten } & \text { B. LED } \\
\text { C. LD } & \text { D. mercury lamp }\end{array}$ \\
\hline 8 & $\begin{array}{l}\text { During the measurement, if a flat line } \\
\text { appears, what should we do? }\end{array}$ & $\begin{array}{l}\text { A. don't pay attention to it } \quad \text { B. add a attenuator } \\
\begin{array}{ll}\text { C. widen the slit } & \text { D. decrease the interval of sampling }\end{array}\end{array}$ \\
\hline 9 & $\begin{array}{l}\text { The blaze wavelength of the grating of the } \\
\text { spectrometer is } \mathrm{nm} \text {. }\end{array}$ & $\begin{array}{lll}\text { A. } 200 & \text { B. } 500 & \text { C. } 800\end{array}$ \\
\hline 10 & $\begin{array}{l}\text { When we are collecting the data, which of the } \\
\text { following opinions is right? }\end{array}$ & $\begin{array}{l}\text { A. We can move the light source forward and } \\
\text { backward. } \\
\text { B. We can change the voltage of the PMT. } \\
\text { C. We can't move the light source, we also can't } \\
\text { change the voltage of the PMT. } \\
\text { D. We can change the voltage of the light source }\end{array}$ \\
\hline
\end{tabular}


Table 2. Judgment questions of experiment on the measurement of the light sources' characters.

\begin{tabular}{|c|l|}
\hline Number & \multicolumn{1}{|c|}{ Questions } \\
\hline 1 & $\begin{array}{l}\text { During the measurement, if the signal is not large enough to analyze, we can widen the slit } \\
\text { substantially. }\end{array}$ \\
\hline 2 & $\begin{array}{l}\text { In order to know how the spectrophotometer works, we can open the lid of the } \\
\text { spectrophotometer during the measurement. }\end{array}$ \\
\hline 3 & $\begin{array}{l}\text { We should run the software of the spectrophotometer after we have turned on the } \\
\text { spectrophotometer. }\end{array}$ \\
\hline 4 & We should turn on the high voltage of the photomultiplier tube before beginning the experiment. \\
\hline 5 & We can move the light source during we are getting the signal. \\
\hline
\end{tabular}

\section{APPLICATION OF THE SOFTWARE AND THE EFFECT ANALYSIS}

\subsection{The teaching proceeding with the APP}

In 2017 and 2018, the APP was used to teach two times. The students must finish watching the teaching video, answer five questions randomized by the APP and get more than 60 scores before they begin the experiment. In the laboratory, the students spend all the time to do the experiment and finish the report. If they find any question about the experiment during they write the report, they can ask the teacher and do the experiment again.

\subsection{The efficiency of the new teaching model}

Because the teacher needn't to introduce the experiment every time, so the efficiency of the teacher is improved. The investigation showed that most students watch the teaching video and finish the preview question on the bus from the third campus to the first campus of our university, so the efficiency of the students is also improved.

\subsection{The effect of the new teaching model}

In order to obtain the effect of the new teaching model, the following two methods were used:

(1) Comparing the scores of the examinations of the experiments that taught by two different teaching model

In order to compare the effects of two teaching methods, the new teaching method is just used to some experiments, and other experiments still use the traditional teaching model. The result shows that the mean score of the experiments that taught by the novel teaching model is 87.5 , it is obviously higher than the mean score of the experiments that taught by the traditional teaching model, which is 82 . The first reason is that the students finish the report in the laboratory, they understand the experiment more deeply. The second reason is that most students watch the teaching video before they take the examination, so they master the related knowledge better.

(2) Doing survey by questionnaire

There are 49 students participate in questionnaire survey. The questions and the results are showed in Table 3 . From this table, we can conclude that most students prefer the novel teaching model and they are satisfied with it. Some students think the APP is inconvenient to use. In the following study, we will use the commercial teaching software, mosoteach, to assistant our teaching.

Table 3. The questions and the results of the survey.

\begin{tabular}{|c|l|l|}
\hline Number & \multicolumn{1}{|c|}{ Questions } & \multicolumn{1}{|c|}{ Results } \\
\hline 1 & $\begin{array}{l}\text { Which teaching model you like better, the } \\
\text { traditional teaching model or the novel teaching } \\
\text { model? }\end{array}$ & $\begin{array}{l}\text { A. the traditional teaching model }(28 \%) \quad \text { B. the novel } \\
\text { teaching model (72\%) }\end{array}$ \\
\hline 2 & What do you think about the teaching video? & $\begin{array}{l}\text { A. detailed properly (47\%) B. should be simpler } \\
(27 \%) \text { C. should be more detailed (26\%) } \\
\text { If you choose B, which part should be more }\end{array}$ \\
\hline
\end{tabular}




\begin{tabular}{|c|c|c|}
\hline & & $\begin{array}{l}\text { detailed?(multiple choice) } \\
\begin{array}{ll}\text { A. the background }(85 \%) & \text { B. the principle }(31 \%) \\
\text { C. the device }(8 \%) & \text { D. the operation }(38 \%)\end{array} \\
\begin{array}{ll}\text { If you choose C, which part should be simpler? } \\
\text { (multiple choice) }\end{array} \\
\begin{array}{ll}\text { A. the background }(15 \%) & \text { B. the principle }(23 \%) \\
\text { C. the device }(45 \%) & \text { D. the operation }(57 \%)\end{array}\end{array}$ \\
\hline 3 & $\begin{array}{l}\text { How long does it take you to watch the } \\
\text { teaching video and finish the preview } \\
\text { questions? }\end{array}$ & $\begin{array}{l}\text { A. less than } 30 \text { minutes }(8 \%) \quad \text { B. about } 45 \text { minutes } \\
(84 \%) \quad \text { C. more than } 60 \text { minutes }(2 \%)\end{array}$ \\
\hline 4 & How do you think about the preview questions? & $\begin{array}{l}\text { A. not too difficult or too easy }(76 \%) \\
(8 \%) \quad \text { C. too easy }(16 \%)\end{array}$ \\
\hline 5 & What do you think about the APP? & $\begin{array}{l}\text { A. easy to use }(45 \%) \text { B. difficult to use }(55 \%) \\
\text { If you choose B, what's the main reason? (multiple } \\
\text { choice) } \\
\text { A. It's inconvenient to use the mobile phone }(22 \%) \\
\text { B. It's inconvenient to use the APP }(67 \%) \\
\text { C. The teaching video is not smooth and easy }(44 \%)\end{array}$ \\
\hline 6 & $\begin{array}{l}\text { Which one has better effect, the traditional } \\
\text { teaching model or the novel teaching model? }\end{array}$ & $\begin{array}{l}\text { A. the traditional teaching model }(24 \%) \text { B. the novel } \\
\text { teaching model }(76 \%)\end{array}$ \\
\hline 7 & $\begin{array}{l}\text { Please list the successful contents of the new } \\
\text { teaching mode. }\end{array}$ & $\begin{array}{l}\text { The most popular answer: } \\
\text { 1.Preview the experiment efficiently, and save much } \\
\text { time for doing experiment; } \\
\text { 2. By watching the teaching video, the student can } \\
\text { understand the difficult knowledge deeply; } \\
\text { 3. The online test can make the students know how well } \\
\text { they master the knowledge. }\end{array}$ \\
\hline 8 & $\begin{array}{l}\text { Please list the contents that needed to be } \\
\text { improved. }\end{array}$ & $\begin{array}{l}\text { The most popular answer: } \\
\text { The APP is used inconveniently. }\end{array}$ \\
\hline
\end{tabular}

\section{CONCLUSION}

With the development of the technologies of computer and internet, some novel teaching models appear for theoretical or practical lessons. The result of our study shows that the efficiency and the effect of the new teaching model with miniexperiment-teaching APP assistant are better than those of the traditional teaching model, although the APP is imperfect.

\section{Acknowledgments}

This work is supported by the education and teaching research undergraduate project of National University of Defense Technology (Grant No. U2018102) and the education and teaching reform research project of Hunan province.

\section{REFERENCES}

[1] http://www.coursera.org/

[2] http://www.udacity.com/

[3] http://www.edx.org/

[4] http://www.xuetangx.com/ 
[5] http://www.icourses.cn/imooc/

[6] Jianhua Shi, Bing Lei, Wei Liu, et al, "Study and practice of flipped classroom in opto-electronic technology curriculum," Proc. of SPIE10452, 104520R, (2017).

[7] Jianhua Shi, Wei Liu, Bing Lei, et al, "Investigation, study and practice of opto-electronic MOOCs," Proc. of SPIE 10452, 1045243 (2017).

[8] LEI Bing, FENG Ying, LIU Wei, et al, "Exploration on cultivating mode of talents with innovation practical ability based on SITP," Research in Teaching, 38(6), 97-111(2015)

[9] Bing Lei, Wei Liu, Jianhua Shi, et al, " Exploration and practice of the cultivation of optoelectronic innovative talents based on the Students Innovation Trainings," Proc. of SPIE 10452, 1045242 (2017). 